\title{
Study on Module Design of Residential Units in Prefabricated Boarding Schools
}

\author{
Qin Di, Xin Zhilei., Gao Pengkun \\ ChangChun Institute of Technology, china
}

\begin{abstract}
This paper aims to respond to the country's call for the development of prefabricated buildings. Taking the middle school student dormitory interior decoration system as the research object, the prefabricated decoration and building modularization ideas are the core. The literature research method and the inductive summary method were used to analyze the residential unit modules, the functional modules and envelope modules they contained, and the combination of modules, which proved that this construction method is more efficient and environmentally friendly. Finally, a residential unit module scheme suitable for boarding school students' dormitories is designed to provide a reference for improving the overall assembly rate of prefabricated student apartments.
\end{abstract}

\section{Introduction}

In recent years, the design schemes, materials and construction techniques of domestic prefabricated buildings have been continuously updated, and the construction methods and industry development of prefabricated buildings have also undergone great changes. Among them, while the external structure assembly system assembly rate is steadily increasing, the assembly rate of most building interior systems is still low. Although prefabricated interiors have opened the market due to their advantages of fast, energy saving, and low emissions, they have been widely used in some public buildings, such as airports, hospitals, exhibition halls. But they are still rarely used in school buildings. At present, the number of boarding schools in China is gradually increasing, and the construction of student dormitories is very considerable.

The student dormitory has the characteristics of relatively simple and regular construction plane. The dormitory unit is highly repetitive and independent, with obvious modular characteristics. Moreover, the building height is usually not high, and the construction scale is relatively large. Therefore, the application of the modular design concept in the construction of student dormitories is conducive to improving the speed and quality of construction and reducing construction costs. [1] Among the various types of spaces in student dormitories, living spaces such as dormitories are the most uniform and repetitive. Therefore, this article chooses to design residential unit modules.

\section{Definition of residential unit module}

\subsection{Concept of residential unit module}

Modular thinking is a new way of thinking, which has the characteristics of diversification and personalization, and can be realized by decomposition and combination. [2] And the design of the residential unit module is to divide and combine the functions required in the student's dormitory at first, then standardize and modularize the parts and components, and finally form a whole. By copying and accumulating this standard module, part of the dormitory building can be completed.

\subsection{Composition of residential unit modules}

If the residential unit module is regarded as a box made of building blocks, the prefabricated envelope structure is a plate that functions as a partition and protection. It is built in the form of modular design, forming a relatively independent space, and using assembly as a technical means to complete its integrity and standardization as a unit. Inside this space, the layout of the furniture is used to form more detailed functional modules, supplemented by hydropower, smart home and other equipment to meet the operating conditions. Finally, a unified environment is formed by hue, lighting, and sound. The whole box, from the outside to the inside, from the actual material to the atmosphere, forms a modular unit, which can be inserted into the existing framework of the building at any time, and can also be decomposed and re-prefabricated at any time within itself. 


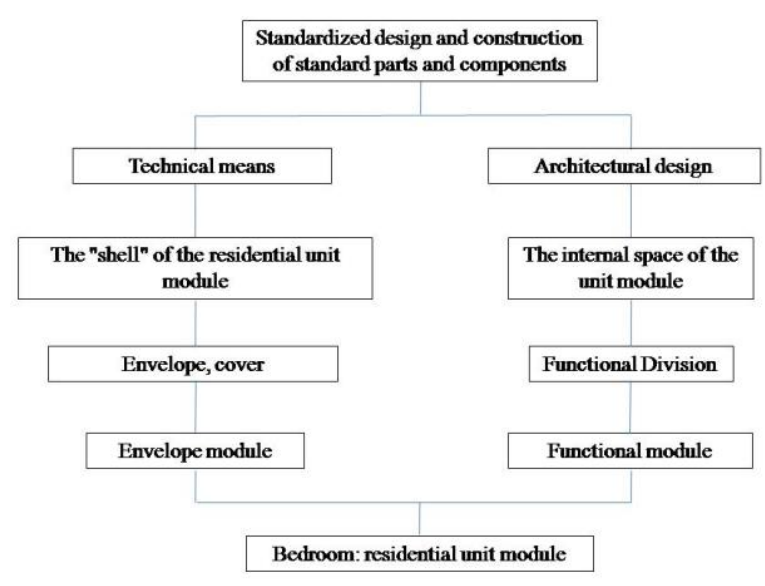

Fig. 1 Unit module structure

\section{Analysis of influencing factors of functional module design}

In ordinary bedrooms, the two main factors affecting the division of functional zones are the functions of the bedrooms and the user's action flow. However, in the prefabricated residential unit module, the functional zone has become a functional module. While the architectural design meets its own expression, it should also make as much judgment and planning as possible for the downstream construction work. Therefore, its design influencing factors also include the principle of modular coordination and standardized design. Each functional module is integrated with a traffic module and wrapped with an envelope module.

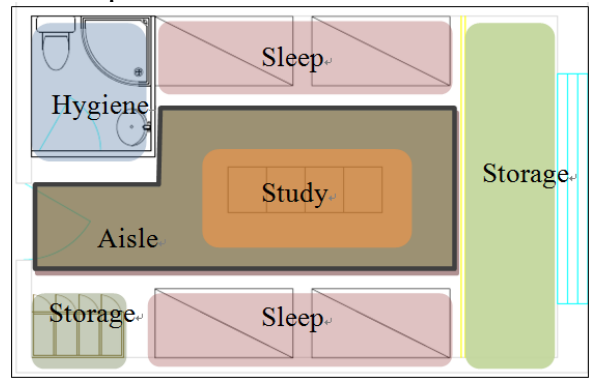

Fig. 2 Schematic diagram of the functions contained in a common bedroom

In the relatively private space of the middle school student's bedroom, its basic function is for students to learn and live. Therefore, the most basic function of the bedroom is sleep, study and storage. On this basis, it can be expanded, and functional modules such as hygiene can be added.

\subsection{Sleeping module}

In boarding schools, the sleeping module in the student bedroom is one of the areas where students spend the longest time, so the size of the bed and its relationship with space should be grasped to create a comfortable resting environment. The sleeping module mainly refers to the bed and the surrounding environment. At present, the beds in domestic student bedrooms are basically divided into single beds, double iron frame beds, and bed-type overall furniture. The size of the beds is basically: $900 \mathrm{~mm} \times 2000 \mathrm{~mm}$. This size is more suitable for adults, and it is a relatively large scale for young people, which is a waste of materials and space.

Table1.Landscape Teen height map

\begin{tabular}{ccc}
\hline Age & Boys' medium height & Girls' medium height \\
11 & $146.01 \mathrm{~cm}$ & $147.36 \mathrm{~cm}$ \\
12 & $152.18 \mathrm{~cm}$ & $152.41 \mathrm{~cm}$ \\
13 & $160.19 \mathrm{~cm}$ & $156.07 \mathrm{~cm}$ \\
14 & $165.63 \mathrm{~cm}$ & $157.78 \mathrm{~cm}$ \\
15 & $169.02 \mathrm{~cm}$ & $158.47 \mathrm{~cm}$ \\
16 & $170.58 \mathrm{~cm}$ & $158.93 \mathrm{~cm}$ \\
17 & $171.39 \mathrm{~cm}$ & $159.18 \mathrm{~cm}$ \\
18 & $171.42 \mathrm{~cm}$ & $160.01 \mathrm{~cm}$ \\
\hline
\end{tabular}

The age range of middle school students is about 11 18 years old. The height range of boys is $146-171 \mathrm{~cm}$, and the height range of girls is $147-160 \mathrm{~cm}$. According to the middle height scale of adolescent men and women, the size of boys 'beds can be set to $900 \mathrm{~mm} \times$ $1900 \mathrm{~mm}$, and the size of girls' beds can be set to $900 \mathrm{~mm}$ $\times 1800 \mathrm{~mm}$, and the space above the beds should not be less than $1300 \mathrm{~mm}$. Regarding the design of the beds, we should consider its due facilities and effectively divide the static and dynamic zones to meet the students' requirements for privacy and domain. [3]

\subsection{Learning Module}

The study space in the bedroom mainly refers to tables and chairs. There are two types of desks: ordinary desks and overall furniture desks. The size of ordinary desks for middle school students is $600 \mathrm{~mm}$ long $\mathrm{x} 420 \mathrm{~mm}$ wide $\mathrm{x} 760 \mathrm{~mm}$ high. The size of the L-shaped desk in the overall furniture is $1450 \mathrm{~mm}$ long $\mathrm{x} 900 \mathrm{~mm}$ wide. Chinese middle school students' schoolwork is basically completed in classrooms and study rooms. Autonomous learning time in the dormitory is short and mostly in the evening. Therefore, the learning space requires less natural light, and artificial lighting is mainly considered.

\subsection{Multifunctional Module}

In the traditional dormitory design, considering the economy, the function of the dormitory is basically monotonous, but now some students prefer to do activities and eat in the dormitory. The new student apartment design has more features, so you can consider setting up a multifunctional space to meet students communication, sports, dining and many other uses. In the limited space of small bedroom, it intersects with the rest space and the learning space. In this case, in order to avoid mutual influences, consider flexible arrangement of the activity space, such as setting a mobile table in a certain area of the bedroom. Put it down when you use it, and usually put it away to facilitate transportation. 


\subsection{Storage module}

Storage space includes: bookshelves, cabinets, hanging cabinets, overall furniture storage, under the bed and other spaces. In fact, the storage space is very flexible and important, and other modules often need to be used with storage. According to GB 50099, it is recommended that the storage space for each person in the living room is $0.50 \mathrm{~m}^{3}$ to $0.80 \mathrm{~m}^{3}$. However, in the boarding school, the students' gradually increasing items may not be taken away in time, and the storage space is tight. This number can be increased appropriately. Inside the unit, considering the dust-proof and visually orderly beauty of the items, the storage space basically occupies inconspicuous, built-in or fragmented spaces, but this also faces the question of whether the design is reasonable and the access is convenient, so the height and range of the storage system must also be accessible and friendly, while increasing demand and resegmentation.

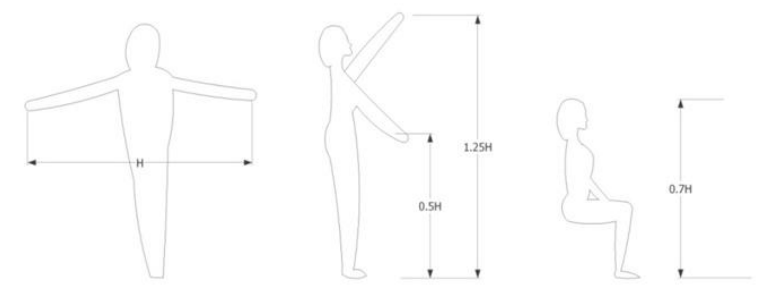

Fig. 3 Body size

Table2. Approximate dimensions of the storage space required for the item

\begin{tabular}{|c|c|c|}
\hline $\begin{array}{l}\text { Personal } \\
\text { items }\end{array}$ & Size & Volume \\
\hline Toiletries & $\begin{array}{c}500 \mathrm{~mm} \times 500 \mathrm{~mm} \times \\
200 \mathrm{~mm}\end{array}$ & $0.05 \mathrm{~m}^{3}$ \\
\hline $\begin{array}{l}\text { Shoes \& } \\
\text { Bags }\end{array}$ & $\begin{array}{c}750 \mathrm{~mm} \times 800 \mathrm{~mm} \times \\
200 \mathrm{~mm}\end{array}$ & $0.12 \mathrm{~m}^{3}$ \\
\hline Clothing & $\begin{array}{c}17500 \mathrm{~mm} \times 550 \mathrm{~mm} \times \\
900 \mathrm{~mm}\end{array}$ & $0.866 \mathrm{~m}^{3}$ \\
\hline Idle luggage & $\begin{array}{c}300 \mathrm{~mm} \times 460 \mathrm{~mm} \times \\
780 \mathrm{~mm}\end{array}$ & $0.107 \mathrm{~m}^{3}$ \\
\hline $\begin{array}{c}\text { Seasonal } \\
\text { bedding, } \\
\text { etc. }\end{array}$ & $800 \mathrm{~mm} \times 500 \mathrm{~mm} \times 600 \mathrm{~mm}$ & $0.24 \mathrm{~m}^{3}$ \\
\hline bookshelf & $\begin{array}{c}300 \mathrm{~mm} \times 900 \mathrm{~mm} \times \\
1000 \mathrm{~mm}\end{array}$ & $0.27 \mathrm{~m}^{3}$ \\
\hline Total & & $1.653 \mathrm{~m}^{3}$ \\
\hline
\end{tabular}

\subsection{Overall bathroom module}

The overall bathroom module is actually a perfect embodiment of the modular idea in the concept of prefabricated decoration. It is designed with a modular system to form a standard module.

The most commonly used forms of dormitory bathrooms for middle school students in China are centralized large bathrooms and separate bathrooms inside the dormitory. Centralized bathrooms have poor cleaning management and lack of privacy and bathing functions. Therefore, in the new student dormitory residential unit module, separate bathrooms can be used as much as possible. In consideration of students' washing habits, to avoid mutual interference during peak hours, the bathroom can be differentiated: the toilet and shower in the student dormitory are separated by sliding doors, and squat toilets should be used. And The wash basin is set separately, which is convenient for several people to use it at the same time without affecting each other.

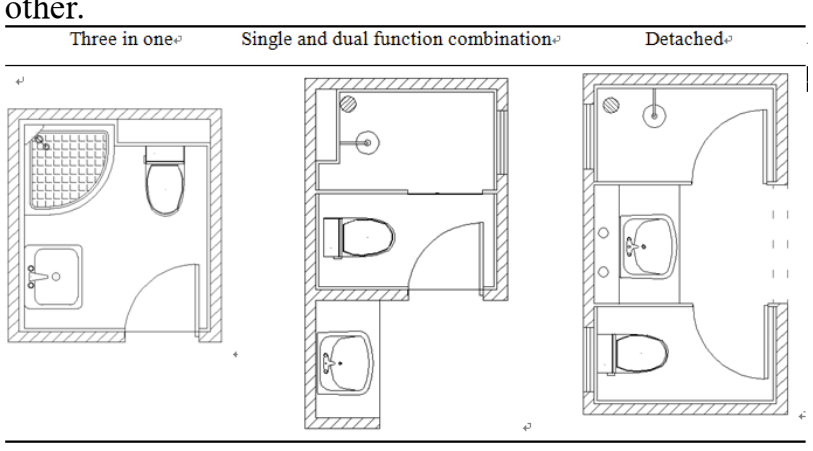

Fig. 4 Overall bathroom layout

Finally, in order to save costs as much as possible, the furniture should be made of materials with certain durability. The materials used should be resistant to dirt, easy to clean, not suitable for bacterial survival, and have a long service life, while ensuring the health and safety of students.

\section{Main points of envelope module design}

The residential unit modules use prefabricated decoration, and the main enveloped modules include interior walls (partition walls), ceilings, and ground. The design of envelope modules needs to be based on the principles of standardization of module design, minimization of module types, diversification of module combinations, and scalability of the combination. [4] As a envelope module, the prefabricated envelope structure also contains the characteristics of disassembly and assembly. It mainly relies on sheet-like parts, which are basically based on modules such as $3 \mathrm{M}$ and $6 \mathrm{M}$ to standardize the design of parts. The surface of the board can be made with different materials and textures, and the currently used board is calcium silicate board mostly. This material is an inorganic material and does not contain harmful substances such as formaldehyde, benzene and DMF. The construction method of the envelope module is dry construction, which has less reliance on traditional decoration techniques, and has lower energy consumption and environmental protection from product production to construction, which is convenient for users to move in as soon as possible.

\subsection{Interior wall (partition wall)}

At present, the traditional non-load-bearing walls are dense and cannot be easily dismantled or modified, while the prefabricated inner wall (partition wall) has 
less pressure on the floor and is easy to install and remove. Prefabricated inner walls (partition walls) are mainly divided into two categories: battens and light steel keels. Taking the prefabricated keel wall as an example, the supporting structure is a detachable keel. The keel is filled with sound-absorbing materials and decorative wall panels are laid to form a whole. The wall board mainly plays the role of heat insulation and sound insulation. Among the same kinds of loose materials, rock wool has the highest NRC coefficient and excellent sound insulation performance. It can increase the sound insulation of the wall by $2 \sim 6 \mathrm{~dB}$. Therefore, rock wool is basically selected as the sandwich material in the structure.

After the factory completes the production of each part of the material and transports it to the construction site, the workers will clean up and pre-arrange the wall panels, confirm the installation starting point, and set up the keel and plank.

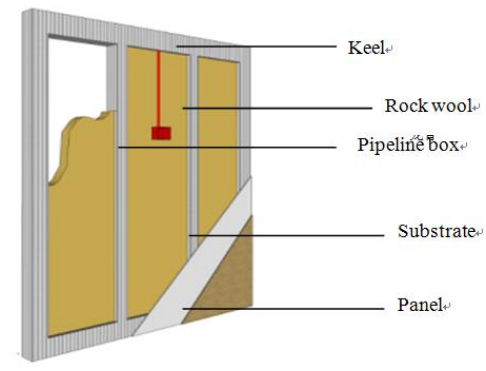

Fig. 5 Interior wall (partition wall)

\subsection{Suspended ceiling}

The main purpose of the bedroom ceiling is to look beautiful, hide the pipeline, and focus on lighting and smoke alarms. The grid keel system is composed of booms and keels. After installation, the panel can be inserted to facilitate line maintenance and can be upgraded with a sound absorption system.

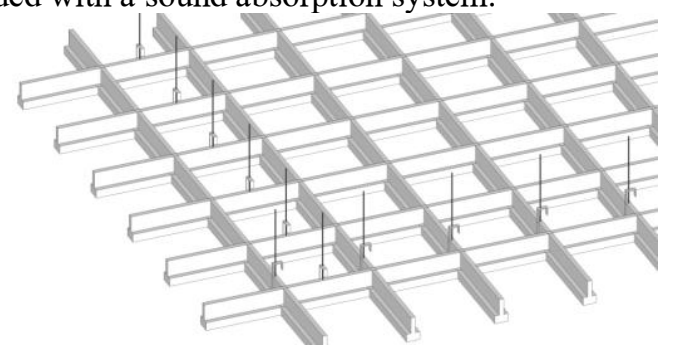

Fig. 6 Grid ceiling

\subsection{Overhead ground}

The biggest feature of the interior system based on the SI concept is the separation of the interior system from the building structure. The prefabricated overhead floor uses anchor bolts. It is used with prefabricated floors and overhead modules to facilitate the laying of pipelines and can be installed in conjunction with the floor heating module. It guarantees that the ground module can be adjusted, dismantled and changed at any time, and has certain flexibility.

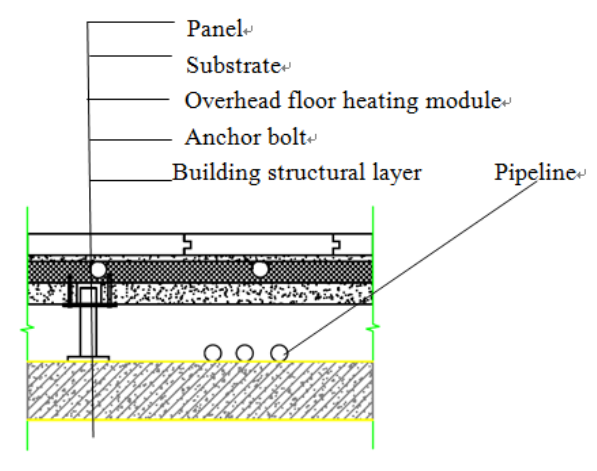

Fig. 7 Ground-to-wall node

\section{Combination and design of residential unit modules}

\subsection{Combination of functional modules}

The functional module combination method is divided into horizontal combination, vertical combination and comprehensive combination. The organization of functional modules must be forward-looking and scalable, and prepare for possible future layout changes.

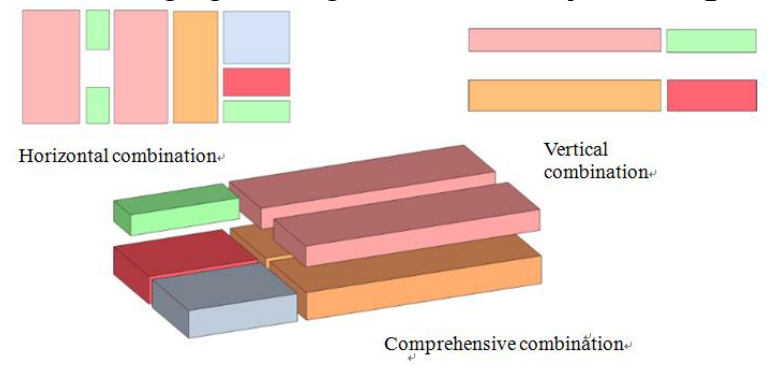

Fig. 8 Functional module combination

Due to factors such as geographical environment and economic conditions, the functions of dormitories for middle school students are not fixed. However, the residential unit module can be basically divided into a basic mode and an auxiliary expansion mode. The basic mode is a sleep module with a learning and storage module, centering on the most basic sleep functions, and is a single, economical bedroom construction mode. The expansion mode is a comprehensive combination of storage, bathroom, drying and storage, which maximizes convenience in a limited space. 


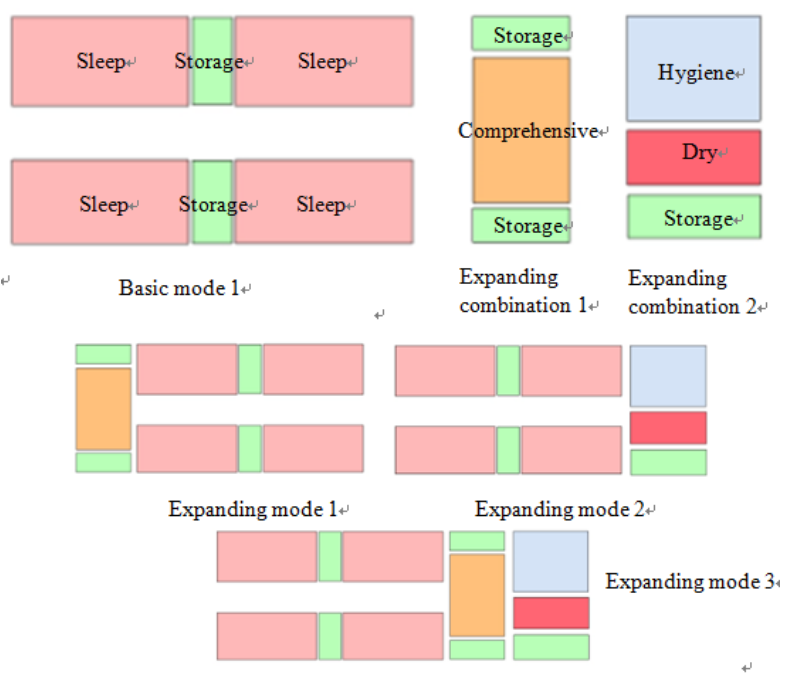

Fig. 9 Basic and expending combinations

\subsection{Residential unit module design}

At present, the four-bed room and the six-bed room are more common. The two-bed room is not cost-effective. The dormitory room with more than six people is not comfortable. This article only uses the four-bed bedroom of middle school students as an example to design the residential unit module.

In the student bedroom, the sleeping module occupies a major position and occupies the largest space. Therefore, the sleeping module is used as the core to carry out the subsequent storage, learning, comprehensive, and bathroom module layout. The layout of the sleeping module includes horizontal design and vertical design, and it is also divided into open, closed and semi-open. Considering the optimal enhancement of privacy and sound insulation, the example sleep module and learning module adopt a vertical design, that is, the overall furniture. When the upper bed is adopted, the clear height of the room should not be lower than $3050 \mathrm{~mm}$. It is assumed here that the clear height of the room is $3300 \mathrm{~mm}$. On this basis, the three dimensions of the interior dimensions of the room set are $2700 \mathrm{mmwide}$ $\times 4200 \mathrm{~mm}$ long, $2700 \mathrm{~mm}$ wide $\times 5400 \mathrm{~mm}$ long, and $3300 \mathrm{~mm}$ wide $\times 6600 \mathrm{~mm}$ long.

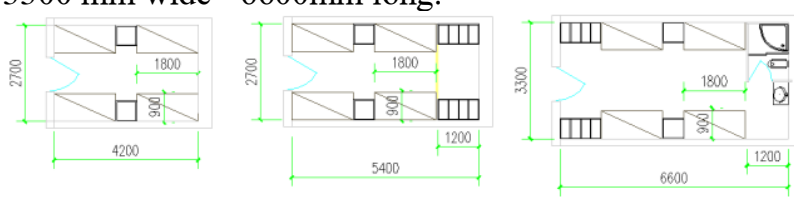

Fig. 10 Extension of residential unit module

The width of the boards on the market is mostly $600 \mathrm{~mm}$, which is convenient for unified design and production. Therefore, in order to achieve close-fitting of the boards and avoid secondary cutting on site, combined with the approximate dimensions of the overall bathroom and balcony, the dimensions of the envelope module and the functional module are designed according to the $3 \mathrm{M}$ module. According to the size of the room, design the size of the enclosing board: the wall board is $3300 \mathrm{~mm}$ long $\times 600 \mathrm{~mm}$ wide ; the floor surface of the bedroom is $600 \mathrm{~mm}$ long $\times 600 \mathrm{~mm}$ wide; the ceiling panel is $600 \mathrm{~mm}$ long $\times 600 \mathrm{~mm}$ wide. The color of the wall panel should be as simple and gentle as possible. Here, beige is selected, and blue curtains with higher gray levels are used. They are quiet and soft, and are suitable for middle school students facing the pressure of further studies. Taking into account the convenience of cleaning and sensory comfort, the floor surface of the bedroom is made of light-colored floor tiles. To reduce glare, small ceilings are matte white.

\section{Conclusion}

The flexibility and expandability of the residential unit module is in line with the fast-paced and diverse needs of modern people. Customize the overall process, reduce consumables and construction time, and save energy and reduce emissions.

With the gradual completion and maturity of prefabricated interior system technology and the gradual standardization of construction procedures, its application range has gradually expanded. For most boarding elementary and junior high schools that can only use student holidays for construction and urgent construction periods, whether it is to renovate the interior of dormitory bedrooms or completely build new dormitory buildings, the application of prefabricated residential unit modules is a good choice. The modularization of living space is a branch and epitome of industrialization of prefabricated buildings. After the products are uniformly standardized, they can enter and industrialization, thereby reducing costs. Research on the design of the residential unit module can provide a certain reference value for the rapid and large-scale improvement of the living environment.

\section{Acknowledgement}

Thanks to Mr. Qin Ling of BeiJing Ba Da Chu Decoration Engineering Co.Ltd. for his information and help during the paper writing process. Also, thanks to my graduate team for their collective cooperation.

\section{References}

1. G.Z.Zhu, B.Hou, Y. Jiang, Shanxi Architecture. J.44, 25(2018).

2. S.S.Xue, Beijing Jianzhu University, D.(2013).

3. Y.L.Zhu, Tianjin University.D.(2006)

4. L.Zhou, Y.D.Tu, Y.P.Zhang, P. Yun, L.N.Tang, Sichuan Building Science Research.J.43,33(2017) 